\title{
EL UNIVERSO FEMENINO EN LA OBRA DE E. ZOLA. AMBIVALENCIA Y CONTRAPOSICIÓN
}

\author{
$M^{a}$ de Gracia Caballos Bejano
}

\begin{abstract}
In this work we have had the intention to show the importance given by E. Zola to the female world, despite most of his important characters are male, excepting Gervaise and Nana. After the introduction about the social and juridical concepts of the XIX century women, about the dealing world in which they are involved, and about the role prostitution and adultery play during this time, the presentation of the female labour world is emphasized, point hardly noticed in other writers in the century. The female ambivalence in which this work is based is centered around two types of women: those whose targets are seduction and their body care, in order to attract men's attention, and those who dedicate their life and body to procreation and education of their children. This is the main women's objetive for the writer and the one that validates her position as the main piece inside family and society.
\end{abstract}

Lo primero que debemos destacar, antes de entrar en el tema que vamos a tratar, es que Emilio Zola, quizás debido a la influencia ejercida por la mujer en su infancia y en su juventud ya que queda huérfano a la edad de siete años, es un escritor de lo masculino más que de lo femenino; sus grandes personajes, a excepción de Nana o de Gervaise, son todos masculinos. Pero estos hombres esculpidos por él tienen una necesidad imperiosa: tịenen hambre de mujer. Debido a ello, el escritor, hombre también y sintetizador de este espíritu de posesión, se siente en cierta manera forzado a crear primeramente unos personajes femeninos destinados a complementar y a satisfacer a estos hombres hambrientos y por otra parte consagrados por entero a complacer su exacerbada ansia de posesión. Para conseguir este objetivo, Zola, bajo la influencia de las artes plásticas, se centra en particular en la minuciosa descripción de sus formas, generalmente voluptuosas y sinuosas, en la pintura de su carne sonrosada y apetitosa que incita a ser devorada. Ofrece así a los lectores una perfecta imitación de la imitación apoyándose especialmente, para una mayor verosimilitud, en la pintura y en la escultura y llegando incluso a la alegoría o a la abstracción.

Para comprender estas dos imágenes ambivalentes y contrapuestas del universo femenino zoliano hay que tener en primer lugar una idea de cómo estaba considerada jurídica y socialmente la mujer del siglo XIX y en qué medio alcanzaba su mayor desarrollo. Los dos papeles fundamentales otorgados a la mujer desde este siglo son el de ciudadana responsable y productora activa (aunque un gran número de trabajos que suelen conllevar una gran responsabilidad les están vetados) y el de madre ya que, como engendradora de vida y como 
educadora, de ella depende el porvenir de la sociedad. Jeanne Dorion lo explica en su libro L'opinion des femmes:

La mission des femmes, de celles qui se sentent appelées, c'est l'apostolat et c'est comme mères qu'elles doivent se devouer pour préparer un avenir meilleur à leurs enfants ${ }^{l}$.

Jules Michelet, uno de los ideólogos de Zola, define en L'amour (1859) las características ideales de la mujer casadera para la sociedad de este momento; sería la que dejara al hombre en completa libertad para moldearla a su antojo y para colmar con ella sus necesidades:

...sencilla y amante... pobre, aislada, poco rodeada de familia. La condición, la educación, son cosas completamente secundarias... Como esposa, la mujer sencilla que uno puede educar un poco, y como hija la mujer creyente, que el padre educará por entero ${ }^{2}$.

Social y jurídicamente hasta este momento la mujer estaba sometida al marido o al padre. A partir de 1881 consigue la mayoría de edad a los 21 años y, si está soltera, a partir de esta mayoría de edad tiene los mismos derechos que los hombres. Sin embargo, la mujer casada sigue sometida al marido y no puede hacer nada sin su autorización.

Las tradiciones regulan todas las uniones matrimoniales y, en este período particularmente, se acercan más a un contrato mercantil, primando esencialmente las condiciones materiales de cada uno de los miembros de la pareja. $\mathrm{H}$. de Balzac, como retratista de la sociedad francesa de principios de siglo, en su obra Le contrat matrimonial, realiza un estudio sociológico del matrimonio mostrándolo más como una transacción económica que sentimental. Esta primacía de lo económico y este desinterés por la pasión amorosa y por las ideas de la pareja conducen inexorablemente hacia el adulterio, considerado como una nueva forma de relación natural entre los sexos. Zola está en contra del adulterio, achacando la falta a la mujer e indicando que el hombre nunca es culpable de caer en él; sin embargo nos dice que ella no debe ser castigada personalmente por el marido.

Esta falta de interés, este sometimiento y esta dependencia al hombre pueden ser conceptuadas como las causas que impulsan a la mujer a considerar el adulterio y la prostitución como una de las salidas más clásicas.

Si nos remontamos a la organización de la sociedad primitiva, vemos cómo con el establecimiento y la ratificación de la unión matrimonial, y posteriormente con su sacramentalidad y su indisolubilidad, nace el adulterio ${ }^{3}$. Pero el adulterio ponía en peligro la estabilidad de la sociedad y como una posible vía de escape a este problema nace la prostitución.

Aunque la prostitución se extiende en cualquier grupo social medianamente desarrollado, se acusa su aumento en particular a fines del siglo XVIII, con la llegada de la mujer campesina

\footnotetext{
${ }^{1}$ Es esta última misión la más característica de la mujer de este siglo como lo afirma Catherine Toubin-Malinas en su tesis doctoral en la que cita esta frase de Deroin. C. Toubin-Malinas, La condition de la femme au XIXe siècle à travers Fécondité d'Émile Zola (Lyon 1979) 23.

${ }^{2}$ M. Benavides, Michelet y la mujer, VII Encuentro De la Ilustración al Romanticismo. Cadiz, América y Europa frente a la modernidad. Universidad de Cadiz (1994) 24-25.

${ }^{3}$ El caso de actantes sujetos femeninos que caen en adulterio es típico de la narración novelada. De este período podemos destacar: H. de Balzac, Le lys dans la vallée (París 1835); Mémoires de deux jeunes mariées (París 1841). G. Flaubert, Madame Bovary (París 1857). É. Zola, La curée (París 1871).
} 
a las ciudades y con la necesidad de encontrar un trabajo para poder sustentarse. La mujer tiene que aprovecharse pues de su cuerpo como motivo reivindicativo para ascender en la escala social o simplemente para poder sustentarse. Por ello podemos considerar que el motivo del auge de la prostitución es debido fundamentalmente al desarrollo del proletariado urbano, a la falta de preparación laboral de estas mujeres, a la escasez de trabajo, a su pobre remuneración y a la existencia de una burguesía rica y poderosa pero cargada de costumbres hipócritas.

Este aumento lleva a dos médicos, entre otros, a interesarse por el estudio de estas mujeres. Restif de la Bretonne escribe en 1769 un tratado regulador en el que explicita las diferentes formas de Amor físico y su reglamentación jurídica. En él indica las formas fundamentales para poder normalizar a las mujeres que viven dentro de la prostitución, mostrando casi como única salida alternativa su educación, lo que evitaría las numerosas enfermedades y peligros físicos a los que la sociedad de este momento se veía inexorablemente abocada. Posteriormente, en el siglo XIX, Alexandre Parent-Duchâtelet escribe De la prostitution dans la ville de Paris considérée sous le rapport de l'hygiène publique, de la morale et de l'administration, donde establece una especie de retrato robot de este tipo de mujer, mostrando las características sociales, familiares y económicas que la impulsan a caer en la prostitución ${ }^{4}$.

Los tipos de mujeres que aparecen en los escritores de este período del siglo XIX son primordialmente tres: la joven huérfana que suele ser acogida por algún familiar que se sirve de ella como criada, la solterona que generalmente es hipócrita, vengativa y cruel y, por último, la prostituta que carece de crueldad pero que, por la injerencia del medio y por la educación, está abocada inexorablemente a un destino funesto y negativo para ella.

En la obra de Zola se explicitan particularmente cuatro tipos diferentes de mujeres, siendo su vida y su desarrollo contrarios, en general, a las mujeres creadas por los otros escritores 5 :

- La jovencita. No hay muchos personajes de esta edad profundizados por el escritor, pero todas ellas tienen un marcado carácter simbólico, teniendo en general una muerte rápida e inesperada. De ellas destacamos Miette, de La fortune des Rougon, que muere a causa de una revolución política en la que se ve inmersa, y Catherine Maheu, de Germinal, que desaparece en medio de una catástrofe natural, mientras que Albine, de La faute de l'abbé Mouret, Jeanne Grandjean, de Une page d'amour, y Angélique, de Le rêve, mueren naturalmente por incongruencias del destino que las determina desde su nacimiento.

- La solterona. Este tipo de mujer no es muy apreciado por Zola, ya que considera que dilapida sus energías y su fuerza inútilmente sin dedicarlas al fin fundamental para el que ella misma ha sido engendrada. Destacamos en particular Pauline Quenu, de La joie de vivre, que vive para mantener la ensoñación continua de su amor pasional plasmándolo en la entrega desinteresada en la mujer y en el hijo de su ser amado.

\footnotetext{
${ }^{4}$ Sobre el problema de la prostitución en este período consultar: H. de Balzac, Splendeurs et misères des courtisanes (1838-1847). J.M. Revilla "Una propuesta de reforma de la prostitución en Restif de la Bretonne", VII Encuentro de la Ilustración al Romanticismo. Cadiz América y Europa ante la modernidad (1994).

${ }^{5}$ Confrontar A. Krakowski, La condition de la femme dans l'oeuvre d'Émile Zola ( París 1974). La autora hace aquí un profundo análisis de la condición psíquica, moral y social de los personajes femeninos en la producción de Zola y nos muestra que todos ellos plaman de una manera contrastada, variada y rica la imagen de la mujer de mediados del siglo XIX.
} 
- La prostituta. No debemos olvidar, como hemos expuesto anteriormente, que este tipo de mujer es una consecuencia del determinismo social. Zola no culpa a la mujer que busca esta salida pero la condena, sin embargo, si se sirve de su cuerpo sólo para enriquecerse. En su obra Les trois villes, muestra que la mujer tiene derecho a todas las reivindicaciones que quiera siempre que no estén en contradicción con las funciones que la naturaleza le ha asignado. De entre todas las que aparecen en su obra destaca Nana, máximo exponente femenino del carácter zoliano, símbolo de la inconsciencia y de la fuerza femenina. La degeneración familiar, unida al alcohol y la influencia del medio, es la causante de su caída en la prostitución y de su carácter vengativo y reivindicativo. Es el adalid de la clase femenina en su lucha contra la opresión a la que el ser masculino la tiene sometida.

- La mujer trabajadora. Es la mayor innovación femenina en la obra de Zola ${ }^{6}$. Este tipo de mujer no es apenas tratado por los otros escritores de este período, dándole este escritor, como adelantado que es a las ideas de su tiempo, un papel representativo, símbolo del importante papel laboral que la mujer va a desempeñar en la sociedad futura. El escritor nos muestra la evolución laboral de la mujer, su preparación y la continua equiparación con el hombre, al que supera en eficacia en diferentes puestos. Esta mujer trabajadora destaca fundamentalmente en tres de sus novelas:

- Germinal. Donde se explicita la dura vida en la que vive este tipo de mujer, desempeñando al mismo tiempo su labor de ama de casa y su duro trabajo en la mina, convirtiéndose para defender sus derechos en una activista social, enfrentándose al fuego de las armas con más ardor que los hombres.

- Le ventre de Paris. En ella se presenta el amplio panorama laboral femenino de un mercado. Destaca el papel de Pauline Quenu, que, de simple vendedora, evoluciona, liberándose de la mediatización familiar, hasta convertirse en propietaria, llegando a ser considerada como la reina de Les Halles, el gran mercado de París.

- Au Bonheur des Dames. Se describe aquí el panorama laboral de unos grandes almacenes, mostrandose la evolución del comercio tradicional a las grandes extenciones comerciales donde, a modo de un gran falansterio, la mujer busca su liberación, ocupando un papel fundamental.

Para poder centrarnos pues en esta dicotomía femenina, no debemos olvidar que, a lo largo de la historia, la mujer se ha encontrado siempre rodeada de un mercado de compraventa. Para poder alcanzar una buena condición social la mujer no encuentra otro camino que el de venderse; debe pagar una dote o poseer un buen título para encontrar un marido y, si no lo posee, la única vía que le queda es su belleza o su cuerpo, de ahí el recurso a la prostitución.

Como la belleza es uno de sus procedimientos de promoción, la mujer debe cuidar su cuerpo y mantenerse deseada, para sostener el ego masculino; por ello abandona el cuidado de los hijos e incluso intenta no tenerlos para no estropear su vida y su cuerpo. A esto es debida la condena y la división fundamental que establece el autor entre sus personajes femeninos,

\footnotetext{
${ }^{6}$ Para profundizar en el tema del trabajo, de las condiciones laborales femeninas y de las costumbres del proletariado, confrontar entre otros: G. Duveau, La vie ouvrière en France sous le Second Empire (París 1946). M.H. ZylberbergHocquart, Féminisme et syndicalisme en France (París)
} 
reprobando a todas aquellas que abandonan la función primordial que la naturaleza ha otorgado al elemento femenino sobre la tierra: la procreación. Zola basa sus principios sobre la familia en las teorías que el vizconde Louis de Bonald fija en su obra Ensayo análitico sobre las leyes naturales del orden social (1800), donde explicita que la vida se organiza alrededor de una triada: el hombre, la mujer y el niño; si se prescinde de alguno de ellos la vida no tiene explicación.

No debemos olvidar que, en este período del siglo XIX, la sociedad está influenciada por la teorías antinatalistas de Malthus, que, aprovechadas por las clases altas, intentan reducir la natalidad entre los pobres como medio de mejorar los problemas sociales. Esto, unido a la alta mortalidad infantil, llevó a un alarmante descenso de la natalidad que produjo en Francia una despoblación inquietante. Zola lucha ardientemente contra esta tendencia acusando a las clases poderosas de su egoísmo y de su explotación del más débil y convirtiéndose en un demógrafo y en un sociólogo para el que la miseria, la prostitución y las diferencias sociales son la responsabilidad de estas clases altas. Para avanzar en estos problemas Zola propone mejorar la vida de las madres solteras, ya que no son sólo ellas las culpables de su problema, sino que que han caído en las trampas tendidas por los hombres. Por boca del utópico Bush, de L'argent, propone que se libere materialmente a la mujer, haciéndose cargo la comunidad del mantenimiento y de la educación de estos niños; y por boca de Denise Baudu, de Au Bonheur des Dames, defiende a las mujeres trabajadoras que queden embarazadas sugiriendo que la empresa les asegure asistencia médica desde el momento en que su embarazo les impida atender con decoro a los clientes de la tienda.

A estos adelantos sociales propuestos en su primera serie hay que añadir las ideas que expone en Fécondité, donde, lejos de une referencia simplemente anecdótica, muestra a las mujeres y a los niños como los elementos más perjudicados de esta política. Para indicar la terapeútica necesaria proyecta los cuatro libros de Les Evangiles, palabra que significa buena nueva y donde predica el nacimiento de una sociedad nueva por medio de una pareja de actantes, Marianne Froment y Mathieu y sus doce hijos, los cuales, al igual que las doce tribus de Israel, forman el pueblo elegido que extenderá a lo largo del mundo la buena nueva de la vida y de la fecundidad. Por lo anteriormente expuesto vemos como para Zola la mujer es la imagen de la vida y su fin es continuarse en sus hijos, reflejando aquí el escritor, como en un espejo, la esterilidad de su matrimonio y lo negativo que esta situación conlleva para él. Los hijos son el motivo justificativo de la unión de una pareja; de este modo justifica él también ideológicamente su relación con Jeanne Rozerot, aunque se haya realizado fuera de la unión matrimonial.

Vemos claramente como en Zola la sexualidad, la mujer, el ser femenino no puede separarse del concepto de madre. El escritor la hace responsable de la evolución de la humanidad ya que, aunque puede propagar algunas taras, su fecundidad es siempre positiva puesto que es a través de ella como el ser humano puede regenerarse. La consecuencia natural de la sexualidad es la concepción del hijo, siendo considerado el placer y el deseo como los medios de los que se vale la naturaleza para conseguir el objetivo de la procreación. Por ello frente al hombre, que para Zola está unido al principio del espíritu, la mujer representa la materia, está unida a la vida, la lleva dentro y es capaz de producirla. 
Siguiendo estas ideas expuestas, vamos a estudiar un grupo de actantes femeninos no perdiendo de vista que estarán siempre englobados dentro de uno u otro de estos grupos anteriormente explicitados y que nos servirán para aclarar esta dicotomía contrapuesta existente en el amplio espectro que forma el mundo femenino zoliano.

Casi todos los actantes femeninos de Zola se mueven de una manera inefable en torno al terreno amoroso. El amor conlleva una necesidad de posesión, es una pulsión que alcanza la plena satisfacción al conseguir la total posesión. Esta consecución del amor lleva emparejada una doble sensación que es al mismo tiempo contrapuesta: en primer lugar positiva y agradable al conseguir, sin impedimento, la posesión del ser deseado; en segundo lugar negativa, pues el acto de posesión es en sí destructivo y va emparejado a un sufrimiento, a una sensación dolorosa que puede empujar a la persona hasta la perversión.

Esta fuerza negativa y ultrajadora vamos a analizarla en particular en tres personajes femeninos de la obra zoliana en los que los instintos y las pasiones clavan de manera emponzoñada su afilado y mortífero aguijón, consumiéndolos lenta pero certeramente:

- Renée Saccard, de La curée, es la Fedra del segundo Imperio, la mujer voluptuosamente desequilibrada y audaz, la encarnación del amor, el sexo y el deseo, de la pasión y la ternura, de la pureza y la lujuria. Para ella, desde su temprana violación, el amor es una sensación prohibida, un sentimiento peligroso que, por el riesgo implícito que conlleva, produce placer y puede conducir a la perversión sexual. Es la búsqueda de esta nueva sensación placentera y pecaminosa la que, por una parte, unida a su ansia de rebelión contra la supremacía masculina, la separa de su marido, que también la expolia, y por otra parte, la arrastra hacia el incesto y la impulsa a mantenerse en él. Dentro del incesto nuestra actante encuentra la forma de dominar al hombre, su amante, feminizándolo, proporcionándole esta acción un aturdimiento de los sentidos, un exacerbado despliegue del deseo, una sensación extraña mezcla de desasosiego y de placer extremo.

Pero esta vida dentro del peligro y el pecado la desengaña, la gasta y la consume física y mentalmente en plena juventud, empujándola inconscientemente, en medio de tormentos morales, hacia la destrucción y la muerte, como si se tratara de un objeto de usar y tirar:

Lo que acabamos de hacer es algo infame, susurró la mujer, desilusionada, con la cara envejecida y seria ${ }^{7}$.

Zola nos muestra que la mujer, cuando está sujeta a la fuerza violenta de la pasión, a una potencia sexual perversa y voraz que incluso la hace detentar la fuerza dominadora masculina, no se detiene ante nada y busca aliados que la ayuden a satisfacer sus deseos. Uno de los principales aliados de Renée es la naturaleza, simbolizada en esta novela en las plantas del invernadero de la casa de la mujer. Dentro del invernadero se produce una simbiosis entre la mujer y las plantas, asimilando cada una de ellas las propiedades y las capacidades de la otra y detentando las fuerzas destructivas de la antropomorfa bestia devoradora que dominaba el invernadero. Las plantas son formas vivas femeninas y cálidas que, a través de sus aromas sensuales y cálidos y la profusión de colores, explicitan incitaciones sexuales, estableciéndose una relación entre la boca voraz de Renée y el rojo sangrante de las flores, la profusión de sus

\footnotetext{
${ }^{7}$ É. Zola, La curée. (París 1971) 215. Las traducciones que aparecen en el texto son nuestras, correspondiendo la página mencionada a la obra en su versión original.
} 
besos y la floración exuberante de las flores, entre sus movimientos animalizados y felinos y los de las hojas:

(Los amantes) permanecían embriagados ante este olor a mujer amorosa que pululaba por todo el invernadero... Sus besos florecían y se marchitaban como las flores rojas de la malva, que duran apenas unas horas, y que renacen sin cesar, parecidas a los labios mortiferos e insasiables de una Mesalina gigante (Zola, 1971: 263-264).

Zola nos muestra que la única salida posible para calmar la lascivia y para poder encontrar la tranquilidad y el reposo es la muerte. La muerte es pues considerada como el último amparo de la conciencia culpable, como el único ente capaz de llevar a cabo de nuevo, por medio del absurdo, la armonización de la persona que se ha dejado arrastar por las redes incontenibles de los instintos con su conciencia.

De este modo Renée, incomprendida e incomprensible, al percibir su falta y descubrir ante el espejo su ajado y desnudo rostro, oculto hasta ese momento por la concupiscencia, se deja atrapar por la meningitis y muere atormentada como consecuencia de su incesto.

Ella había vivido en el país de la vergüenza, y era castigada con el abandono de su cuerpo, con la muerte de su ser que agonizaba... Con las manos juntas, ella sollozaba a la caída de la tarde (Zola 1971: 395, 434).

- Nana, de Nana, es la pintura del vicio tomado en su acepción más popular; es una especie de diosa pagana, un mito sensual que domina desde su altar corporal ante el que todos los hombres se postran rindiendo culto de adoración y pleitesía. Pero es más aún: se la considera como la Gran Debilitadora, la Muerte Tentadora, el precipicio delicioso y vacío donde uno se hunde placenteramente; es una hermosa trampa donde el hombre se anula.

Desde el punto de vista de los sentimientos es una joven sin pasión, un fermento destructivo que experimenta con todos los vicios sin sentir por ello ninguna sensación, convirtiéndose en un principio desorganizador de cualquier sociedad; es el vértigo de la perdición, de la destrucción y de la muerte. En ella se materializa la conjunción visceral entre el dinero y el sexo, siendo el elemento catalizador de la decadencia de los órganos dirigentes del segundo Imperio.

A lo largo de la dilatada obra de Zola vemos múltiples ejemplos que nos muestra el miedo que el autor siente ante un cuerpo femenino; de ahí la sensación continua de que la mujer es la causa de los males del hombre. Y si aparece desnuda ante él, por una parte desencadena un mundo de instintos y violencia difícil de atajar y, por otra parte, con este arma natural es capaz de conseguir cualquier cosa del ser masculino que, ancestralmente, como elemento dominador, la ha usado, la ha explotado y utilizado para sus necesidades, empujándola a la corrupción y a la esclavitud a la que ella tiene que someterse. Nana usa a menudo de este recurso al desnudo para dejar al hombre inerme ante sus poderes ${ }^{8}$.

\footnotetext{
${ }^{8}$ Sobre el personaje de Nana como el símbolo de la mujer irresistible, imagen plástica de la depravación del segundo Imperio -plasmación metonímica de la indolente y devoradora Salomé bíblica, símbolo de la tradición judáica y del imperio romano- y sus diferentes apariciones desnuda o dejando casi traslucir su cuerpo a través de un velo semitransparente que le ayuda en su proceso de seducción y conquista. Confrontar:

F. Meltzer, Salomé and the Dance of Writing: Portraits of Mimesis in Literature, (University of Chicago 1987).

J. Beizer, "Uncovering Nana: The Courtesan's New Clothes", Esprit Créateur, nº 25 (1985), 42-53.
} 
Nuestro actante femenino, que puede ser reconocido como el placer hecho persona por su exuberancia corporal y por la sensualidad que desprenden sus curvas, se sirve pues de esta arma otorgada gratuitamente por la naturaleza para satisfacer sus instintos de venganza y de opresión ocultos desde el principio de los tiempos por el sexo femenino. Esta actante se apropia del carácter vengativo, más propio de la imagen masculina, y deja aflorar toda su enjundia y su fuerza de mujer subyugada a lo largo de los años.

El ataque que Nana despliega es doble, ya que va dirigido, no sólo contra el hombre, ya que ella ha sido testigo de la continuas vejaciones y ultrajes que ellos han infligido a su madre, sino también contra la clase superior que, del mismo modo que el hombre ha esclavizado y afrentado a la mujer, ha oprimido y se ha servido de la clase trabajadora a la que ella pertenece desde el principio de la sociedad. Por ello Nana se erige en estandarte de la venganza femenina y aprovecha su cuerpo y su belleza para someter, devorar y destruir a los hombres y todo lo que ellos personifican, al igual que contra la aristocracia, a la que llega a dominar convirtiéndose en su principio desorganizador.

Sin embargo veremos como, incapaz de dominar los poderes y las pasiones que su cuerpo levanta, de dominadora se convierte en objeto de devoración, siendo consumida por la muerte, destructora suprema de cualquier ser vivo y de la que, en un principio, ella era el adalid terrenal.

Nana sabe la fuerza que reside en su cuerpo, el poder de atracción que tiene entre el elemento masculino, su capacidad para exigir y cuándo tiene subyugado a un hombre a sus pies sin defensa alguna. En general se aprovecha de las debilidades de sus acompañantes después de la realización del acto sexual, convirtiéndolos en sus esclavos o dejándolos en la más absoluta pobreza física, psíquica y moral. Atacó los denominados pilares de la sociedad del XIX, como son las finanzas, la aristocracia, la iglesia y la familia, demostrando que todas las clases y estamentos sociales sucumben ante los mismos vicios.

Nana, antes de convertirse en cortesana seductora, era ya una jovencita perdida socialmente pues, muy joven aún, tiene un hijo. Esto podría salvarla del mundo de vicios en que vive al colaborar con el hecho de la continuación natural, pero, al nacer fuera del vínculo matrimonial, el niño está predeterminado y abocado por la naturaleza desde su nacimiento a una muerte prematura, hecho conceptualizado como castigo: el niño es propenso a enfermedades e infecciones que le causarán la muerte. Por otra parte el dolor de su partida servirá a su madre, Nana, como elemento expiatorio y como motivo de depresión.

Este actante femenino está podrido, al igual que sucedió con Renée, y por ello abocadao a la destrucción. Hay una serie de características que la introducen en este mundo degenerativo: una falta de continencia en el terreno sexual; una caída continuada en un mundo de vicios, no sólo vive como cortesana sino que cae en el sadismo sexual, personificado especialmente en la imagen del conde Muffat al que obliga a convertirse en sus ensoñaciones sexuales en un animal; y su entrada en el lesbianismo por sus relaciones con la prostituta Satin. De este cambio consecutivo de amantes se ve abocada, al igual que su compañera Satin, a una enfermedad infecciosa que después de una terrible descomposición la conducirá a la destrucción final, a la muerte. 
Zola nos presenta plásticamente a Nana como un virus insaciable que contamina y destruye todo lo que toca; nos describe a este actante insaciable y depravador, a esta personificación de la corrupción con las siguientes palabras:

Nana es una especie de capilla ardiente; en el centro, y como en el fondo de un tabernáculo, el sexo de la mujer; a su alrededor una multitud de hombres prosternados, arruinados, vaciados, embrutecidos... Una jauría detrás de una perra; el poema siniestro de los deseos del macho?.

- Séverine, de La bête humaine. En esta novela la bestia personificada en Jacques, el deseo en Séverine y la máquina en la Lison funcionan de una manera equivalente, instaurando un "ménage à trois" que conlleva siempre connotaciones negativas. La actante es una víctima innata, lleva el drama en su piel; predispuesta al asesinato, se convierte en asesina directa o indirectamente por interés o por celos. Este actante femenino es presentado primeramente como un ser dócil y delicado, es la caracterización perfecta de la mujer casadera amorosa y amante, capaz de producir tranquilidad e incapaz de inferir mal a ningún ser vivo. Sin embargo esta personalidad femenina se perturba bajo el efecto de su pasión insaciable y, para poder satisfacer sus mórbidos deseos, llega incluso a instigar a su amante al crimen como medio de alcanzar un desconocido placer. A causa de sus instintos desencadena el drama pasional, incurre en adulterio y, esta falta le induce a caer en el mundo de las pasiones más bajas e ignominiosas, las cuales la introducen en una vorágine destructora que de una manera inexorable va a provocar su propio asesinato.

Ya hemos indicado anteriormente que la visión del cuerpo femenino, a causa de la excitación sexual, desencadena la violencia masculina haciendo aflorar en el hombre la bestia humana que lleva dentro. Así Séverine, por la exuberancia de su cuerpo, disfruta despertando en Jacques Lantier su inconsciente animal, un sentimiento de posesión y destrucción que alcanza su éxtasis cuando consuma el asesinato apuñalando el cuerpo poseído. La visión de la sangre y del cuerpo sin vida de la mujer amada apaga todos sus anteriores instintos, restituyendo su mente a la tranquilidad inicial. Séverine, que mata por placer, sufre la misma suerte que sus víctimas, siendo asesinada por las manos de su amante después de entregarse a él. En este actante femenino, como en las evidenciadas anteriormente, la satisfacción de la pasión y la excitación de los deseos la conducen a la destrucción:

(A Séverine) la había matado, la poseía, como había deseado poseerla desde hacía mucho tiempo, por entero, hasta aniquilarla ${ }^{10}$.

De estas tres mujeres desencadenadoras de los disturbios pasionales del hombre por medio de la exaltación de los instintos y de los deseos pasamos al universo opuesto, a las mujeres que se sirven de su cuerpo para favorecer la acción natural de la procreación ayudándose de su cuerpo y del desarrollo de la pasión amorosa. De entre el amplio universo que aparece en la obra zoliana vamos a destacar a tres de ellas:

- Albine de La faute de l'abbé Mouret, es la Eva naturalista que crece libre y sin ataduras. Por una parte esta mujer es la revivificación del mito antiguo que asocia a la mujer con la caída y la castiga con la muerte; por otra parte, es la personificación de la belleza y de la libertad

${ }^{9}$ H. Guillemin, Présentation des Rougon-Macquart (París 1964) 168.

${ }^{10}$ É. Zola, La bête humaine (París 1972) 392. 
natural, el símbolo del amor salvaje, sin ataduras ni prejuicios, y de la sexualidad exuberante a causa de la educación liberal que ha recibido:" ( Albine) es el tipo de la mujer flor natural que cura y regenera ${ }^{11}$.

Con su belleza y la ayuda del Paradou, mezcla de vegetación frondosa y de agua cristalina, es capaz de devolver la vida natural a Serge Mouret, joven sacerdote enfermo que esconde su insatisfacción sexual y las necesidades ardorosas de su constitución masculina en su ensoñación y en su adoración por la Virgen, de la que Albine es físicamente la plasmación terrenal.

$\mathrm{Al}$ lado de su joven amante, renacido en medio de la naturaleza y representante de la masculinidad desprovista de su lado negativo, conoce su transformación de niña a mujer, representando el triunfo de la belleza y de la juventud, alcanzando la plena felicidad en su relación y consiguiendo fructificar esta unión en medio del parque y de la ensoñación de la fecundidad que se desprende de todos sus rincones y que empuja a la pasión. Es la representante de "la fille-fleur, de la fille-rose" que exhala vida y perfume a su paso. Este tema de la unión de la mujer a lo vegetal es la continuación del mito antiguo en el que la virgen y la inocencia se asimilan a la flor y que se repite en la producción de Zola. Albine, identificada en el parque a las plantas, no sólo perfuma y produce olores placenteros como las flores sino que, como ellas, también produce salud y vida. Son las flores y las plantas las que despiertan en ella su fuerza y la empujan a la sexualidad. Desconoce el mal y no cree que nadie pueda detentarlo. Por ello, abandonada por su renacido amante -que se enclaustra y se fortifica en la iglesia que la sumergió en la locura y en la enfermedad y donde reina la muerte-, no comprende el mal o el pecado que ella ha cometido y, ante la incompresión de su destino, busca la vida a través de la muerte por medio de una metamorfosis vegetal que la transforma en flor, mezclándose con la naturaleza e incorporándose a la vida del Paradou en el momento de su muerte pero revivificándose posteriormente de la tierra.

- Clotilde de Le docteur Pascal, es la representación novelada de Jeanne Rozerot. Es la plasmación de la mujer ideal para Zola, la encarnación de la madre; representa el triunfo del amor y es el origen de la regeneración familiar, ya que será la persona encargada de salvar en su descendencia a la saga de los Rougon-Macquart, al igual que Jeanne al otoñal Zola. Su educación liberal hace que se desarrolle naturalmente, lejos de las ataduras en las que las convenciones sociales y la educación religiosa mantienen a las jóvenes de mediados del siglo XIX.

Enamorada de su tío y educador, el doctor Pascal, hombre maduro y consagrado a su profesión humanitaria, se fija como objetivo prioritario que su tío se enamore de ella. Con los dones que su sexo le ha otorgado, con la interconexión entre la ternura y la sensualidad que su cuerpo desprende, consigue despertar la pasión y el deseo en el cuerpo y en la mente del doctor, hombre angustiado por su trabajo y cuya vida ha sido devorada por su obra; logra rejuvenecerlo y revivificarlo, proporcionándole una segunda juventud donde poder desarrollar su virilidad y haciéndole olvidar los problemas y las taras que pululan por las tres ramas de su familia y de las que Clotilde está milagrosamente indemne; por último, lo libera al mismo

\footnotetext{
${ }^{11} \mathrm{Ph}$. Hamon, Zola, romancier de la transparence (París 1983) 391.
} 
tiempo de sus problemas infantiles y de la opresión y del influjo a que su madre, la dominante Madame Rougon, lo tiene sometido. Vemos como la obra de Pascal y su trabajo sobre la herencia familiar son la proyección y el equivalente de la obra de Zola.

Tenemos que aclarar por ello que esta unión que Zola refleja aquí y la evolución de su actante masculino, el doble del escritor, no son más que la realización novelada de la unión del escritor con Jeanne Rozerot, mucho más joven que él pero que lo enriquece y lo revivifica como hombre, fructificando su relación con dos hijos que lo rejuvenecen y que dan validez a esta unión ${ }^{12}$.

Esta relación fuera del matrimonio le sirve para cambiar algunas de sus ideas sobre las relaciones entre parejas explicitadas antes por él mismo y justificar que se puede vivir respetablemente con una mujer aunque la unión no esté regulada por la ley. La unión entre dos seres no debe ser un vínculo que los mantenga aprisionados, sino algo natural que los mantenga libres dentro de esta unión.

De la unión de los dos actantes nacerá un hijo que, al igual que Clotilde, estará libre de taras, siendo el encargado de salvar y regenerar a la familia.

- Marianne Froment de Fécondité ${ }^{13}$, hace de su vientre femenino el altar de la fecundidad; aunque sea pobre, es fecunda y rica a causa de su vientre. Zola hace converger en este actante las funciones de la diosa madre de las civilizaciones antiguas con las de la madre virgen de los cristianos. Para ello debe abandonar los trabajos que la alejan de estas funciones y que le impiden desarrollar plenamente el papel que la naturaleza le ha acordado. Además de ser fecunda, la mujer debe de favorecer la estabilidad de la pareja a través de su amor, de su dulzura y de su consagración al hogar, siendo el complemento efectivo del hombre y dándole el equilibrio y la alegría de vivir que necesita para alcanzar la plena felicidad y la libertad. Fundamentándose en todos estos principios: “... la madre de familia y la joven esposa amante son felices y libres" ${ }^{\prime 14}$.

Al conseguir su propia libertad está preparada para que el hombre consiga también la suya:" Solamente la mujer liberada puede liberar al hombre" $\left({ }^{15}\right)$.

La feminidad de la mujer se ve particularmente aumentada con la llegada periódica de la sangre menstrual que ella hace fructificar con la maternidad. Para Michelet esta sangre transforma al elemento femenino de mujer-flor en mujer-fruto y si la mujer no sabe aprovechar esta riqueza natural y la desperdicia o la inutiliza es finalmente condenada. Esta pérdida puede transformarla de ser productivo en disipador y negativo.

\footnotetext{
12 Debemos señalar aquí que su hija Denise y su hijo Jacques nacen a fines de septiembre de 1889 y 1891 , fecha en que ya tiene en su mente el último libro de la serie, Le docteur Pascal, publicado en 1893 y que muestra un cambio profundo en su concepción narrativa. En esta obra refleja lo que vive y siente más que lo que imagina y presiente, como sucedía en las novelas anteriores.

${ }^{13}$ A partir de Les Quatre Évangiles, Zola, animado por la felicidad que disfruta en su relación con Jeanne Rozerot fructificada con dos hijos, desarrolla un optimismo lírico mostrando una visión patriarcal y bíblica de la familia representada en el matrimonio formado por los Froment. B. L. Nicholas indica que en esta última serie Zola canta en particular: "les louanges du travail, de la fécondité et de la justice sociale" (B. L. Nicholas (1969) 169)

${ }^{14}$ Ch. Jennings. "Zola féministe?", Cahiers naturalistes, 44 (1972) 172.

${ }^{15}$ ZOLA, Émile: 1966. Vérité. Cercle du livre précieux, oeuvres complètes, tomo VIII. París, p. 1249.
} 
Para no caer en este error, Marianne Froment convierte su vientre en un tabernáculo de la fecundidad, no desperdiciando la riqueza que su cuerpo porta; vive según los preceptos establecidos por las leyes naturales y no conoce la pérdida de sangre menstrual, ya que en el momento en que termina con el período de lactancia se queda de nuevo embarazada.

$\mathrm{Al}$ vientre, como símbolo de la fecundidad, hay que unir el seno. Las mujeres que no tienen pecho son consideradas por el autor como enfermas y normalmente son frígidas, tienen un mal carácter, son infecundas o son malas madres, puesto que, aunque son capaces de procrear, no pueden continuar dando la vida a sus hijos por medio de la leche que sale de sus senos, en estos casos inertes. No debemos olvidar que esta leche es una especie de savia natural que, como un río inagotable y lleno de vida nutre, al hijo y lo prepara para posteriormente, con su trabajo, fecundar la tierra. La leche materna es una verdad primaria que contiene unos principios positivos biológicos, dietéticos, inmunológicos y bacteriológicos para el niño.

Sin embargo un pecho abundante, aunque es el símbolo y una de las causas del erotismo, no es siempre indicio de fecundidad si no va unido a la aptitud a la maternidad y puede ser, sin embargo, a causa de su inútil derroche, un ente negativo y la causa de que los instintos se desarrollen de una forma incontenible, impulsando como ya hemos visto al actante femenino hacia la muerte.

Vemos como el culto al seno y sus características fisiológicas son, junto a la maternidad y a la deificación de la mujer fecunda, el centro de la nueva religión que Zola despliega en Fécondité.

Este líquido nutricional que sale del pecho femenino tiene la misma función que, para la tierra, los canales de irrigación que el hombre abre en el campo ${ }^{16}$; del mismo modo que éstos hacen fructificar la tierra, así alimenta la madre a su hijo con la leche portadora de vida que genera su cuerpo. Esta capacidad nutricional que exhala de su cuerpo emanador de vida, sirve al mismo tiempo de nutriente durante toda su vida a Marianne que, a la edad de 87 años:

... se conserva aún bella, con la belleza sana de antes ... y con los senos sólidos que habían alimentado a todo un mundo ${ }^{17}$.

Apreciamos claramente cómo para el escritor la maternidad es el mayor elemento causante de la felicidad femenina; por medio de ella la mujer consigue una salud plena, un bien absoluto, puesto que es considerada como el elemento natural que fomenta la unión de la pareja y que consigue la continuidad del mundo y su salvación. Con el nacimiento de sus hijos y su posterior descendencia, Marianne y su marido Mathieu serán los causantes de la regeneración de la sociedad y los culpables de su nueva concepción.

Marianne et Mathieu volvieron a recuperar la alegría de su creación, la paz de su obra acabada, pródiga e inagotable. No poesían nada más que la felicidad de haber dado todo a la vida....Más allá de los mares, la leche había extendido, desde el viejo suelo de Francia, hasta las inmensidades del África virgen, la nueva y gigante Francia de mañana (Zola 1957: 750-751).

\footnotetext{
${ }^{16}$ Recordemos que también para la filosofía hindú el agua es la semilla fecundante tras el apareamiento del Cielo y dela Tierra.

${ }^{17}$ É. Zola, Fécondité (París 1957) 727.
} 
Podemos concluir diciendo que el personaje femenino, considerado como la imbricación de estos dos entes ambivalentes y opuestos explicitados a lo largo de nuestro trabajo, es para este escritor el instrumento dócil, armonioso, realizador y reconciliador de las diferentes tendencias del yo viril; es capaz de colmar plenamente las ansias de posesión y de dominación del sexo masculino, primando sobre todo ello su capacidad reproductiva y maternal, ya que a través de ella podemos conseguir la continuación del mundo y su salvación. Como rúbrica nos vale la definición que Zola aplica a la mujer y a su función, encarnada en la figura de Clotilde-Jeanne:

... ella era la esperanza. ¿Una madre que da el pecho a su hijo no es la imagen del mundo continuado y salvado $?^{18}$.

\footnotetext{
${ }^{18}$ É. Zola, Le docteur Pascal (París 1971) 500.
} 


\section{BIBLIOGRAFÍA}

A. Baccar, "Le thème de l'éducation de la jeune fille d'après les romanciers du XIXe. et d'après Zola en particulier", Cahiers de Tunisie, $n^{\circ}$ XXV, 3e. et 4e. trimestre (1974).

D. Baguley,"Du naturalisme au mythe: l'alchimie du docteur Pascal", Cahiers naturalistes, $\mathrm{n}^{\circ}$ 48 (1987), 141-163.

C. Becker, "Quelques documents sur la jeunesse d'Émile Zola à Aix-en-Provence", Cahiers naturalistes, $n^{\circ} 55$ (1981), 169-175.

C. Becker et J, Gaillard, Au Bonheur des Dames de Zola. Analyse critique (París 1982).

J. Beizer, "Uncovering Nana: The Courtesan's New Clothes", Esprit Créateur, nº 25 (1985), 42-53.

Ch. Bernheimer, "Huysmans: writing against (female) nature", Poetics today, vol. 6, n 1-2 (1985),311-324.

P. Brooks, “Le corps-récit: ou, Nana enfin dévoilée”, Romantisme, nº 18 (1989), 67-86.

P. Buvik, "Nana et les hommes", Cahiers naturalistes, n 49 (1975), 105-124.

P. Carles et B. Desgranges, "Le cauchemar de l'éducation des filles", Romantisme, vol. 18, n $^{\circ}$ 63 (1989), 23-28.

J. C. Charvoz, Le monde imaginaire de Zola d'après les Rougon-Macquart. Le retour du mythe. Presses universitaires de Grenoble (Grenoble 1980).

I. Chessid, "Au seuil du désir. Le dévoilement de la transgresion chez Zola", Cahiers naturalistes, $n^{\circ} 70$ (1996), 7-18.

U. Dethloff, "Émancipation sociale et patriacat utopique", Kwartalnik Neofilologiczny, vol. 34, $\mathrm{n}^{\circ} 2$ (1987), 131-144.

Ch. Jennings, “Zola féministe?”. Cahiers naturalistes, nº 44 (1972), 172-187.

Ch. Jennings , L'Éros et la femme chez Zola. De la chute au paradis retouvé. Klincksieck (París 1979).

A. Krakovski, La condition de la femme dans l'oeuvre d'Émile Zola. Nizet (París 1974).

C. Malinas, "Le culte du sein dans Féconditê". Cahiers naturalistes, nº 60 (1986), 171-185.

J. H. Matthews, "Une source possible de Nana? Le ménage parisien de Restif de la Bretonne", Cahiers naturalistes, $\mathrm{n}^{\circ} 12$ (1959), 504-506.

F. Meltzer, Salomé and the Dance of Writing: Portraits of Mimesis in Literature, (University of Chicago Press 1987).

J. Michelet, L'amour, (París 1859).

T. Moreau, "Noces d'or: l'économie anti-malthusienne dans l'oeuvre de Zola", Romantisme, $\mathrm{n}^{\circ}$ 40 (1983), 153-165.

F. Naudin-Patriat, "Les classes laborieuses face à l'institution du mariage dans les RougonMacquart”, Cahiers naturalistes, nº 40 (1976), 191-201. 
B. L. Nicholas, Zola, en J. Cruickshank, French Literature and its Background, vol. 5 (Londres, 1969).

R. J. Niess, "Le thème de la violence dans les Rougon-Macquart", Cahiers naturalistes, no 42 spécial (1971), 131-139.

R. J. Niess, "Émile Zola: la femme au travail”, Cahiers naturalistes, nº 50 (1976), 40-58.

R. J. Niess, "Zola et le capitalisme: le darwinisme social”, Cahiers naturalistes, nº 54 (1980), 57-68.

J.M. Revilla, "Una propuesta de reforma de la prostitución en Restif de la Bretonne", VII Encuentro de la Ilustración al Romanticismo. Cadiz, América y Europa ante la modernidad (1994), 577-587.

A. J. Salvan, "Quatre lettres de Zola à sa femme (1895)". Cahiers naturalistes, nº 41 (1971), 75 85.

N. Schor, "Mythe des origines, origine des mythes: La fortune des Rougon". Cahiers Naturalistes, $n^{\circ} 52$ (1978), 124-134.

H. Suwala, Naissance d'une doctrine. Formation des idées littéraires et esthétiques de Zola (1859-1865). (Varsovia 1976).

R. Ternois, "Les Zola. Histoire d'une famille vénitienne". Cahiers naturalites, nº 18 (1961), 4970.

C. Toubin-Malinas, La condition de la femme au XIXe siècle à travers Fécondité d'Émile Zola (Lyon 1979).

H. Weinberg, "Les femmes du peuple de Francis: une nouvelle source de L'Assommoir?". Cahiers naturalistes, $\mathrm{n}^{\circ} 39$ (1970), 61-69.

A. Wilson, Émile Zola: an introductory Study to his novels. Secker and Warburg (Londres 1952). 
